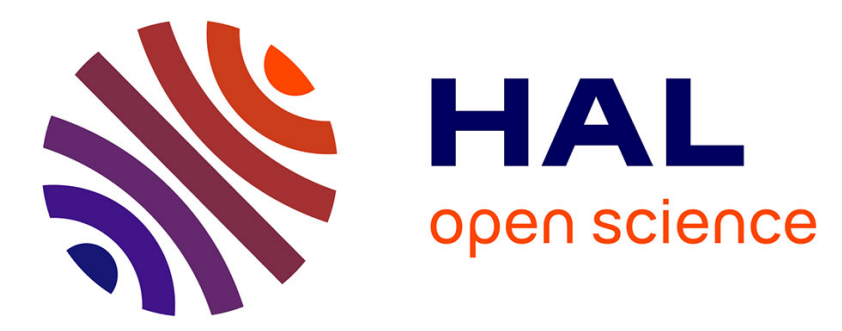

\title{
Neuregulin 1 improves glucose tolerance in adult and old rats
}

K. Caillaud, N. Boisseau, Gaël Ennequin, V. Chavanelle, M. Etienne, Xiaojian Li, Philippe Denis, Dominique Dardevet, Alain Lacampagne, P. Sirvent

\section{- To cite this version:}

K. Caillaud, N. Boisseau, Gaël Ennequin, V. Chavanelle, M. Etienne, et al.. Neuregulin 1 improves glucose tolerance in adult and old rats. Diabetes \& Metabolism, 2016, 42 (2), pp.96-104. 10.1016/j.diabet.2015.08.003 . hal-01595084

\section{HAL Id: hal-01595084 \\ https://hal.science/hal-01595084}

Submitted on 2 Dec 2019

HAL is a multi-disciplinary open access archive for the deposit and dissemination of scientific research documents, whether they are published or not. The documents may come from teaching and research institutions in France or abroad, or from public or private research centers.
L'archive ouverte pluridisciplinaire HAL, est destinée au dépôt et à la diffusion de documents scientifiques de niveau recherche, publiés ou non, émanant des établissements d'enseignement et de recherche français ou étrangers, des laboratoires publics ou privés. 


\title{
Neuregulin 1 improves glucose tolerance in adult and old rats
}

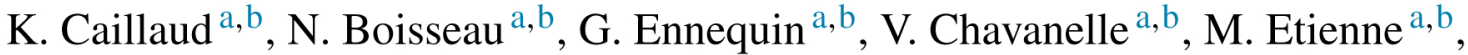

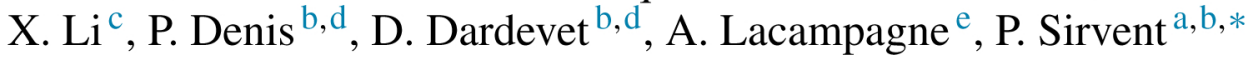 \\ a Université Clermont-Auvergne, université Blaise-Pascal, EA 3533, laboratoire des adaptations métaboliques à l'exercice en conditions physiologiques et \\ pathologiques (AME2P), BP 80026, 63171 Aubière cedex, France \\ ${ }^{\mathrm{b}}$ CRNH-Auvergne, 63001 Clermont-Ferrand, France \\ ${ }^{\mathrm{c}}$ Zensun Sci \& Tech Ltd., Shanghai, China \\ ${ }^{\mathrm{d}}$ INRA, UMR1019, unité de nutrition humaine, 63000 Clermont-Ferrand, France \\ e CHRU Montpellier, U1046 INSERM, UMR CNRS 9214, université de Montpellier, 34295 Montpellier, France
}

\begin{abstract}
Aim. - Studies both in vitro and ex vivo of rodent skeletal muscle have highlighted the potential involvement of neuregulin 1 (NRG1) in glucose metabolism regulation, yet nothing is known of the role of NRG1 in systemic glucose homoeostasis. For this reason, it was hypothesized that systemic delivery of NRG1 might improve glucose tolerance and that the effect might be age-dependent.

Methods. - Glucose tolerance tests were performed in 6-month-old (adult) and 22-month-old (old) male Wistar rats 15 min after a single injection of either NRG1 $(50 \mu \mathrm{g} / \mathrm{kg}$ ) or saline (controls). Skeletal muscle and liver samples were also collected 30 min after the acute NRG1 or saline treatment, while the phosphorylation status of ErbB receptors and AKT was assessed by Western blotting.

Results. - Acute NRG1 treatment decreased the glycaemic response to an oral glucose load in both adult and old rats. NRG1 injection did not activate ErbB receptors in skeletal muscle, whereas phosphorylation of ErbB3 and AKT was markedly increased in the liver of NRG1-treated adult and old rats compared with controls.

Conclusion. - This study shows that NRG1 has a possible glucose-lowering effect in the liver and via an ErbB3/AKT signaling pathway. This NRG1 effect is also maintained in old rats, suggesting that the NRG1/ErbB signaling pathway might represent a promising therapeutic target in insulin resistance states.
\end{abstract}

Keywords: Ageing; ErbB; Glucose homoeostasis; Liver; NRG1; Skeletal muscle

\section{Introduction}

Neuregulin (NRG) growth factors belong to a complex family of proteins that is structurally related to epidermal growth factor

Abbreviations: NRG1, neuregulin 1; ErbB, erythroblastic leukaemia viral oncogene homologue; OGTT, oral glucose tolerance test; AUC, area under the curve; HIRI, hepatic insulin resistance index; MISI, muscle insulin sensitivity index; VEH, vehicle (saline).

* Corresponding author at: Université Blaise-Pascal, laboratoire des adaptations métaboliques à l'exercice en conditions physiologiques et pathologiques (AME2P), bâtiment Biologie B, 24, avenue des Landais, BP 80026, 63171 Aubière cedex, France Tel.: +00334734071 33;

fax: +0033473405062.

E-mail address: pascal.sirvent@univ-bpclermont.fr (P. Sirvent).
(EGF). Four $N R G$ genes have been identified (neuregulin 1-4), and more than 15 distinct membrane-associated or soluble isoforms result from alternative splicing and differential use of the promoter of the NRG1 gene, the most studied of the four NRGs [1]. Neuregulin 1 (NRG1) isoforms are expressed somewhat ubiquitously by cells of endothelial and mesenchymal origin, and are critical for cellular proliferation, survival, migration and differentiation [2]. NRG1 is essential for the development and maintenance of the nervous system [3], heart [4], skeletal muscle [5] and liver [6]. Most NRG1 isoforms contain a transmembrane domain, and all have a bioactive extracellular EGF-like domain [1]. Proteolytic cleavage may lead to release of the EGF-like domain, which can bind to and activate the class-I tyrosine kinase receptors called "erythroblastic leukaemia viral 
oncogene homologues" (ErbBs). Four receptors make up this family (ErbB 1-4); however, NRG1 only binds to ErbB3 and ErbB4. Phosphorylation of tyrosine residues in the ErbB cytoplasmic domain initiates diverse downstream signaling events, notably the phosphatidylinositol 3-kinase (PI3K)/AKT pathway $[7,8]$.

Although most studies of NRG1 have focused on its myogenic and neurotrophic properties, it has been suggested that NRG1 can also influence glucose metabolism [5], particularly in skeletal muscle, the major site of insulin-stimulated glucose disposal. For instance, NRG1 increases glucose uptake in L6E9 myotubes and isolated strips of soleus muscle [9]. Also, chronic exposure to NRG1 improves insulin sensitivity in L6E9 and C2C12 myocytes [10]. On the other hand, in liver, the main organ involved in blood glucose homoeostasis, insulin and NRG1 appear to have competitive, non-synergistic effects. Indeed, in rat liver, insulin decreases NRG1 expression and impairs its binding to receptors through a PI3K-dependent pathway $[11,12]$. In addition, in obese ob/ob mice, ErbB transactivation induces hepatic insulin resistance [13]. Therefore, the complex relationship between NRG1 and insulin in muscle and liver raises the question of NRG1 influence on systemic glucose homoeostasis.

Ageing is one of the physiological states associated with glucose homoeostasis impairment [14]. In ageing myocardium, restoration of the NRG1/ErbB pathway has been suggested to mediate the positive effects of caloric restriction, an intervention that improves glucose homoeostasis and insulin sensitivity, and increases the lifespan, too $[15,16]$. Interestingly, a strong relationship independent of phylogeny has been found between the maximum lifespan of rodent species and NRG1 and ErbB4 expression in the cerebellum [17,18]. This suggests that NRG1, through specific effects on brain function or in the entire body, could be a major determinant of rodent longevity [18]. Ageing also regulates the ErbB pathway in Caenorhabditis elegans (a roundworm) [19], while a progressive age-related decline of ErbB4 expression has been observed in the ventral midbrain of rats [17]. Therefore, the NRG1/ErbB signaling pathway could be involved in age-related metabolic impairment.

The aim of the present study was to determine whether acute NRG1 administration affects blood glucose homoeostasis in adult and old rats. To test the hypothesis that NRG1 has a systemic hypoglycaemic effect and that the effect is age-dependent, the effects of an intravenous (i.v.) injection of NRG1 on glucose and insulin responses to an oral glucose challenge were investigated in adult and old rats. NRG1/ErbB signaling was also assessed in liver and skeletal muscle following the acute NRG1 administration to determine the mechanisms involved in NRG1 effects on glucose homoeostasis.

\section{Methods}

\subsection{Animals}

Animal maintenance and experimental procedures were in accordance with the current legislation on animal experimentation, and were approved by the local ethics committee for animal experimentation (Auvergne, C2EA-02). Old (22-month-old; $n=10)$ and adult (6-month-old; $n=6)$ male Wistar rats (Janvier Labs [CERJ], Le Genest-Saint-Isle, France) were kept in temperature-controlled $\left(20-22^{\circ} \mathrm{C}\right)$ cages and reversed light-dark cycles (8.00 pm to $8.00 \mathrm{am}$ ), and had free access to water.

\subsection{Neuregulin-1}

To evaluate NRG1 effects, the EGF-like domain of human NRG1 ( $\beta 2 \mathrm{a}$ isoform; residues Ser177 to Glu237) was provided by Zensun Science and Technology Ltd (Pudong, Shanghai, People's Republic of China) in a saline solution at $1.25 \mathrm{mg} / \mathrm{mL}$. Immediately before i.v. injection, the solution was diluted with more saline to $50 \mu \mathrm{g} / \mathrm{mL}$ (final concentration).

\subsection{Oral glucose tolerance tests (OGTTs) and metabolic measurements}

OGTTs were carried out over 2 weeks. Rats (adult and old) were fasted overnight $(12 \mathrm{~h})$ and then received either a saline (VEH) or NRGI injection $15 \mathrm{~min}$ before glucose loading by gastric gavage ( $2 \mathrm{~g} / \mathrm{kg}$ of body weight). Half the animals (randomly chosen) were treated with NRG1 and the other half with VEH during the first OGTT. The rats in the NRG1 group were then moved to the VEH group, and vice versa, for the second OGTT. Thus, ultimately, all animals received one injection of NRG1 and one injection of VEH. Blood samples were collected from the tail vein at 15, 30, 60, 90 and $120 \mathrm{~min}$ after glucose loading, and centrifuged at $6000 \mathrm{G}$ for $5 \mathrm{~min}$ for plasma collection. Plasma samples were stored at $-80^{\circ} \mathrm{C}$ until further use. Plasma insulin was measured with an ELISA assay kit (ALPCO, Salem, NH, USA).

Blood glucose levels were determined, using a glucometer, $15 \mathrm{~min}$ before the OGTT $(-15)$ at the time of glucose loading $(0)$, and then at 15, 30, 60, 90 and 120 min after loading (Accu-chek Performa, Roche Diagnostics, Basel, Switzerland). Glucose and insulin responses were expressed as:

- area under the curve (AUC), calculated by the trapezoidal method (total AUC);

- net AUC, calculated after subtracting the baseline concentration.

The homoeostasis model assessment index as a marker of insulin resistance (HOMA-IR) was calculated using the following formula: [fasting plasma insulin $(\mathrm{mIU} / \mathrm{L}) \times$ fasting blood glucose concentration $(\mathrm{mmol} / \mathrm{L})] / 22.5$. The product of the net AUC for blood glucose multiplied by the net AUC for plasma insulin during the first $30 \mathrm{~min}$ of the OGTT was calculated and used as the hepatic insulin resistance index (HIRI) [20]. The rate of blood glucose concentration decay from its peak value to its nadir divided by the mean plasma insulin concentration during the OGTTs was also calculated and used as a muscle insulin sensitivity index (MISI) [20]. 


\subsection{Body composition}

The day before the rats were sacrificed, their body composition was assessed with an EchoMRI ${ }^{\mathrm{TM}}$ 3-in-1 instrument (Echo Medical Systems, Houston, TX, USA).

\subsection{NRG1 injections and euthanasia}

One week after the OGTTs, half the rats were randomly assigned to the NRG1 group (three adult and five old mice) and the other half to the VEH (control) group (three adult and five old mice). For the biochemical experiments, the rats were anaesthetized with $1 \mathrm{~mL} / \mathrm{kg}$ pentobarbital and then euthanized by decapitation 30 min after i.v. injection of NRG1 or VEH, following a 12-h fast. The gastrocnemius muscle and liver were dissected and immediately frozen in liquid nitrogen.

\subsection{Protein extraction}

Frozen samples $(50 \mathrm{mg})$ were crushed in a Potter-Elvehjem tissue grinder placed on ice with $1 \mathrm{~mL}$ of lysis NP40 buffer [50 mM Tris- $\mathrm{HCl}, \mathrm{pH} 7.5 ; 150 \mathrm{mM} \mathrm{NaCl} ; 1 \%$ (v/v) Nonidet P-40; $1 \mathrm{mM}$ EDTA; $5 \mathrm{mM}$ sodium pyrophosphate; $1 \mathrm{mM}$ sodium orthovanadate; $50 \mathrm{mM}$ sodium fluoride] supplemented with freshly added protease and phosphatase inhibitor cocktails (ThermoFisher Scientific, Pittsburgh, PA, USA). Homogenates were centrifuged at $14,000 \mathrm{G}$ for $10 \mathrm{~min}$, and the supernatants collected and stored at $-80^{\circ} \mathrm{C}$. Supernatant protein content was measured by the Bradford method, using a dye reagent (Bio-Rad Laboratories, Hercules, CA, USA) and bovine serum albumin (BSA) as the standard (Sigma-Aldrich Corp., St. Louis, MO, USA), diluted with lysis buffer to a final concentration of $30 \mu \mathrm{g} / \mathrm{mL}$.

\subsection{Western blot analysis}

Western blotting was carried out to measure protein expression in the liver and gastrocnemius samples. Antibodies against ErbB1, p-ErbB1 (Tyr1173), ErbB2, p-ErbB2 (Tyr1248), ErbB3, p-ErbB3 (Tyr1328), ErbB4 and p-ErbB4 (Tyr1056) were purchased from Santa Cruz Biotechnology (Santa Cruz, CA, USA). Antibodies against AKT, p-AKT (Ser473), p42/p44, phosphorylated p42/p44 (Thr202/Tyr204), PKC $\xi$ and p-PKC $\xi$ (Thr410) were obtained from Cell Signaling Technology (Danvers, MA, USA). Protein samples were diluted with Laemmli buffer and separated using Mini-PROTEAN TGX Stain-Free gels (Bio-Rad). After transfer onto PVDF membranes using Trans-Blot Turbo transfer apparatus (Bio-Rad), the membranes were blocked with 5\% BSA solution in Tris-buffered saline $(\mathrm{pH}$ 7.5 ) with $0.1 \%$ Tween 20 (TBST) at room temperature for $1 \mathrm{~h}$. Membranes were incubated overnight at $4{ }^{\circ} \mathrm{C}$ in $5 \%$ BSA with primary antibodies (1/1000 dilution for all antibodies except anti-ErbB antibodies, which were diluted to $1 / 250$ ), followed by an appropriate horseradish peroxidase-conjugated secondary antibody in TBST at room temperature for $1 \mathrm{~h}$. Enhanced chemiluminescence (ECL) reagents (Bio-Rad) were used for signal detection, and digital images were acquired using the Molecular Imager ChemiDoc XRS System (Bio-Rad) and normalized using the total protein normalization (TPN) method provided by the Stain-Free Blot technology [21]. When quantifying the phosphorylated proteins, the protein content was first normalized before calculation of the phosphorylation ratio, and the results expressed as relative to control.

\subsection{Statistics}

Statistical analyses were performed using Statistica software (version 8; StatSoft Inc., Tulsa, OK, USA). Data are presented as means \pm SEM. The Mann-Whitney test was used to compare body composition, blood glucose, plasma insulin and HOMA-IR values between adult and old rats. After checking variance homogeneity with Bartlett's test, two-way analyses of variance (ANOVAs) were used to compare AUC values, HIRI and MISI indices, and protein expression levels in the four groups. ANOVA with repeated measures was performed where appropriate (glucose and insulin responses following glucose loads). When a significant effect was found, post-hoc multiple comparisons were made using Tukey's post-hoc analysis. Statistical significance was set at 0.05 .

\section{Results}

\subsection{Body composition, fasting blood glucose and plasma insulin levels}

Analysis of the morphological characteristics and metabolic measurements of adult and old rats (Table 1) showed that weight, lean mass $(\mathrm{g})$ and fat mass ( $\mathrm{g}$ and \%) were significantly higher in the old rat group $(n=10)$ than in the adult group $(n=6 ; P<0.05)$. However, fasting glucose, insulin levels and HOMA-IR index did not differ across groups $(P=0.21, P=0.95$ and $P=0.95$, respectively).

Table 1

Morphological and metabolic characteristics of adult and old rats.

\begin{tabular}{lll}
\hline & $\begin{array}{l}\text { Adult } \\
(n=6)\end{array}$ & $\begin{array}{l}\text { Old } \\
(n=10)\end{array}$ \\
\hline Age & 6 months & 22 months \\
Weight $(\mathrm{g})$ & $452.5 \pm 17.9$ & $544.0 \pm 17.8^{\mathrm{a}}$ \\
Lean mass (g) & $402.6 \pm 19.8$ & $444.0 \pm 29.1^{\mathrm{a}}$ \\
Lean mass (\%) & $88.9 \pm 2.9$ & $81.6 \pm 4.1^{\mathrm{a}}$ \\
Fat mass (g) & $49.9 \pm 13.7$ & $100.0 \pm 21.1^{\mathrm{a}}$ \\
Fat mass (\%) & $11.0 \pm 2.7$ & $18.3 \pm 3.9^{\mathrm{a}}$ \\
Fasting blood glucose (mmol/L) & $4.8 \pm 0.3$ & $4.6 \pm 0.3$ \\
Fasting plasma insulin (mIU/L) & $20.6 \pm 4.5$ & $23.8 \pm 14.2$ \\
HOMA-IR & $4.3 \pm 1.0$ & $5.0 \pm 3.4$ \\
\hline
\end{tabular}

Blood was collected at rest from the tail vein of male Wistar rats for blood glucose and plasma insulin measurements. Body composition was assessed by an EchoMRI 3-in-1 instrument (Echo Medical Systems, Houston, TX, USA). Values are expressed as means \pm SEM. HOMA-IR: homoeostasis model assessment for insulin resistance, calculated as fasting glucose $(\mathrm{mmol} / \mathrm{L}) \times$ fasting insulin $(\mathrm{mIU} / \mathrm{mL}) / 22.5$. 

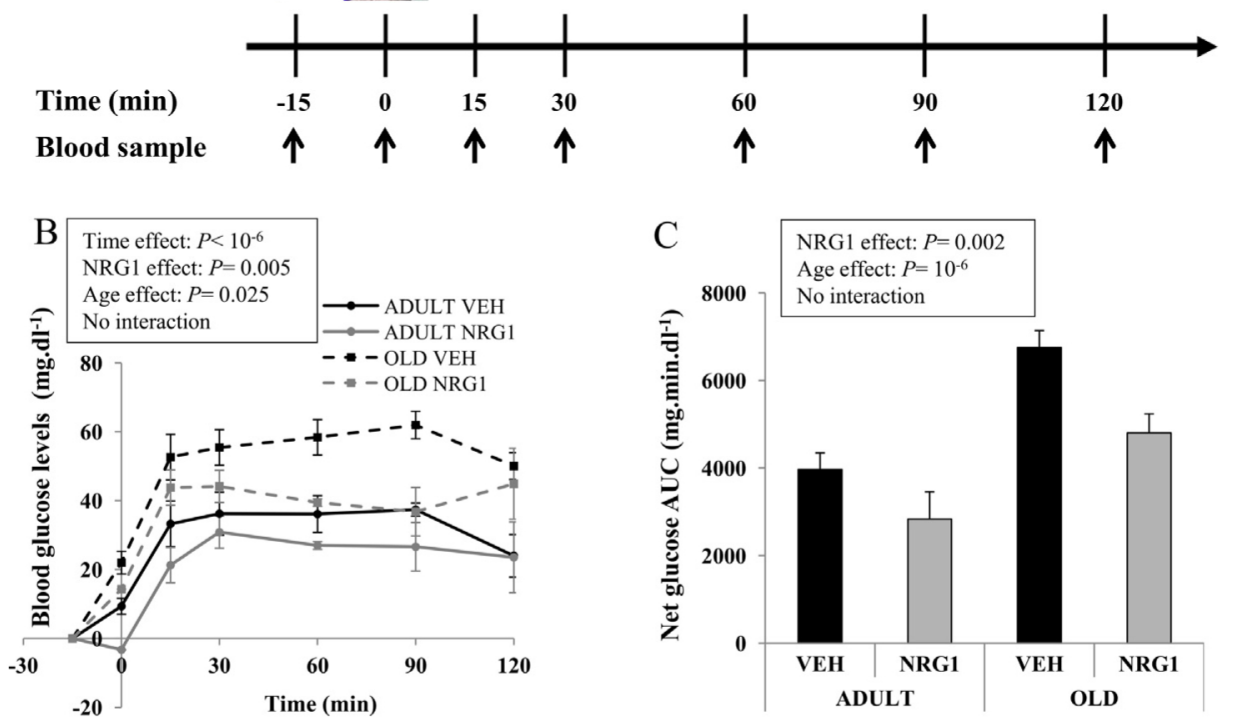

Fig. 1. Effects of acute injection of neuregulin 1 (NRG1) on blood glucose levels during an oral glucose tolerance test (OGTT) in adult and old rats. A. After $12 \mathrm{~h}$ of fasting, adult $(n=6)$ and old $(n=10)$ rats received an intravenous (i.v.) injection (tail vein) of either saline $(0.9 \% \mathrm{NaCl}, \mathrm{VEH})$ or NRG1 $(50 \mu \mathrm{g} / \mathrm{kg})$, followed $15 \mathrm{~min}$ later by an oral glucose load $(2 \mathrm{~g} / \mathrm{kg}$ ). Blood was sampled at different time points for measuring concentrations of glucose (shown here) and insulin (see Fig. 2). B. Blood glucose concentrations in the NRG1 and VEH groups during the OGTT after subtracting baseline concentrations. C. Net glucose AUC in the four rat groups. Values are means \pm SEM.

\subsection{OGTT results}

Fasted adult and old rats received either $50 \mu \mathrm{g} / \mathrm{kg}$ of NRG1 or saline solution (VEH) by i.v. injection $15 \mathrm{~min}$ before oral glucose loading $(2 \mathrm{~g} / \mathrm{kg})$. Blood glucose and plasma insulin concentrations were then measured at different time points over $120 \mathrm{~min}$ (Fig. 1A).

\subsubsection{Glucose response}

There was no significant difference in fasting blood glucose levels between groups (Table 1). After the oral glucose load, glycaemia significantly increased in all rats (time effect: $P<10^{-6}$ ). Nevertheless, blood glucose concentrations during the OGTT were significantly lower in adult (both NGR1 and VEH groups) vs old rats (NRG1 and VEH groups; age effect:
$P=0.025$; Fig. 1B) and in NRG1 - vs VEH-treated animals, independent of age (NRG1 effect: $P=0.005$; Fig. 1B). No significant interaction between time, age and NRG1 was detected.

Similarly, net glucose AUCs were higher in the old than in the adult groups independent of treatment (age effect: $P<10^{-6}$, Fig. 1C), although they were lower in NRG1-treated rats than in saline-treated animals (NRG1 effect: $P=0.002$ ). No significant interaction (age $\times$ NRG1) was noted for either total or net AUCs.

\subsubsection{Insulin response}

There was no significant difference in fasting plasma insulin levels between groups (Table 1). After the oral glucose challenge, plasma insulin levels significantly increased in all groups (time effect: $P<10^{-6}$ ), although they were more elevated in old vs adult rats (age effect: $P=0.019$; Fig. 2B). Plasma insulin
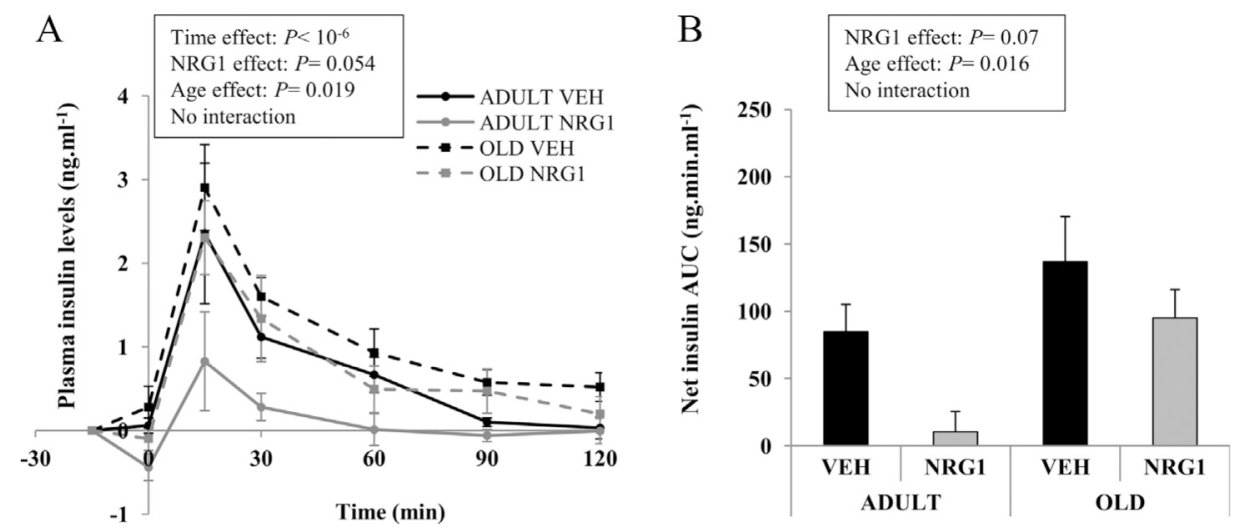

Fig. 2. Effects of acute injection of NRG1 on plasma insulin levels during OGTTs in adult and old rats. A. Plasma insulin concentration in the NRG1 and VEH groups during the OGTT after subtracting baseline concentrations. B. Net insulin AUC in the four groups. Values are means \pm SEM. 
levels tended to be lower in NRG1-treated than in VEH-treated rats (NRG1 effect: $P=0.054$; Fig. 2B). No significant interaction between time, age and NRG1 was detected.

Similarly, net insulin AUCs were higher in the old vs adult groups (age effect: $P=0.016$; Fig. $2 \mathrm{C}$ ). On the other hand, no significant difference in net insulin AUC values was observed between NRG1- and VEH-treated animals ( $P=0.07$; Fig. 2C). No significant interaction (age $\times$ NRG1) was noted for either total or net insulin AUCs.

\subsubsection{HIRI and MISI}

To further explore the mechanism by which NRG1 might influence whole-body glucose homoeostasis, hepatic insulin resistance and muscle insulin sensitivity indices (HIRI and MISI, respectively) were calculated during the OGTTs. HIRI was significantly lower in adult and NRG1-treated animals compared with old and VEH-treated rats $\left(P<10^{-4}\right.$ and $P=0.034$, respectively; Fig. $3 \mathrm{~A}$ ), and no interaction (age $\times$ NRG1) was observed. MISI was not affected by either age or NRG1 treatment (Fig. 3B).

\subsection{Biochemical analyses}

The mechanism by which NRG1 might influence glucose homoeostasis was investigated by assessing, in liver and skeletal muscle (gastrocnemius), the basal level of ErbB receptors and also the phosphorylation ratios (phosphorylated ErbB/total ErbB protein level) $30 \mathrm{~min}$ after i.v. injection (tail vein) of either $50 \mu \mathrm{g} / \mathrm{kg}$ of NRG1 or VEH solution. Key downstream proteins of the ErbB signaling pathway (AKT, MAPK and PKC $\xi$ ) were also evaluated.

Basal expression levels of ErbB receptors were different between the liver and skeletal muscle. ErbB1 and ErbB3 levels were almost 10 -fold and two-fold higher, respectively. Conversely, the ErbB4 level was two-fold higher in skeletal muscle than in liver. ErbB2 was weakly expressed in skeletal muscle and almost absent in the liver (not shown).
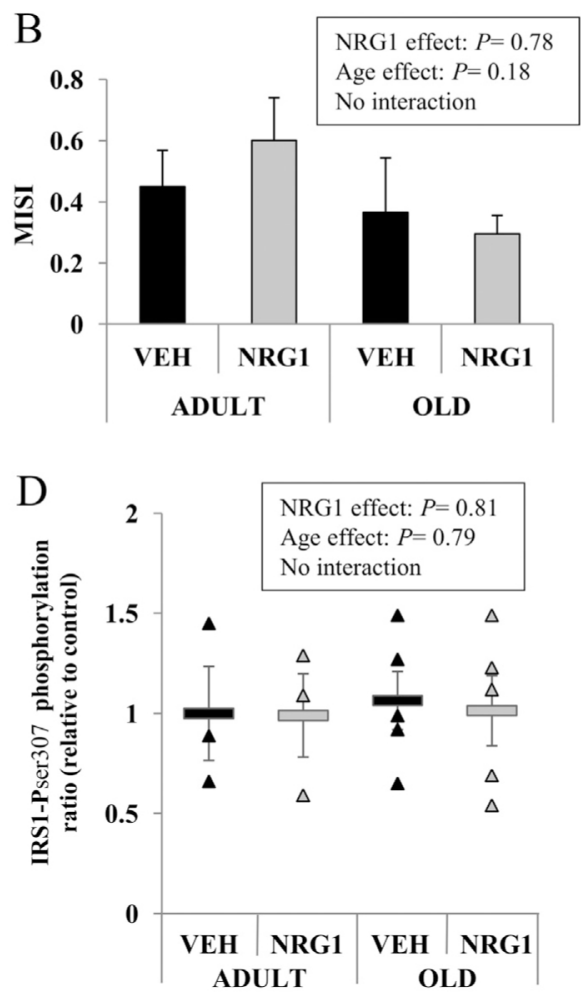
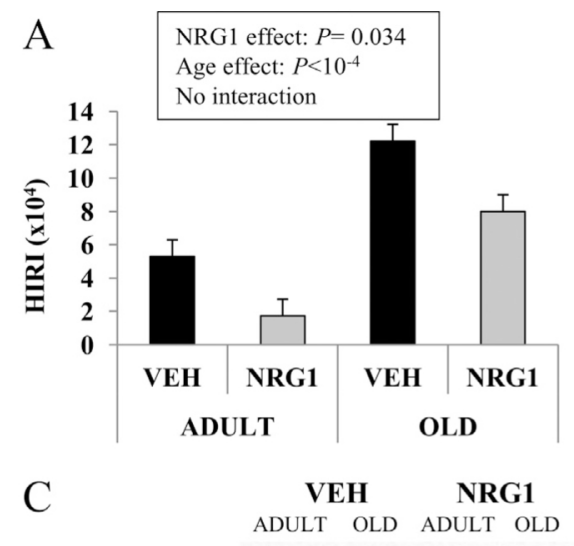

IRS1-p(Ser638)

IRS1-p(Ser307)

IRS1

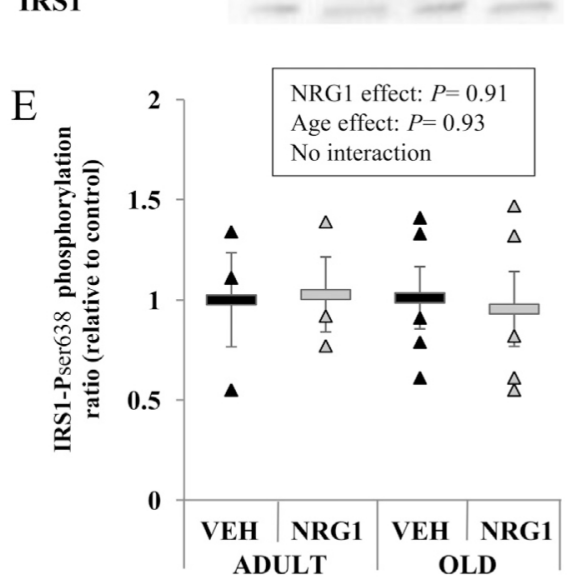

Fig. 3. Effects of acute injection of NRG1 on HIRI and MISI in adult and old rats during OGTT. A. The hepatic insulin resistance index (HIRI) was calculated as net AUC of blood glucose concentrations (0-30 min) multiplied by net AUC of plasma insulin concentrations (0-30 min). B. The muscle insulin sensitivity index (MISI) was calculated as the decay in blood glucose concentration from peak to nadir during OGTT (dG/dt) divided by mean plasma insulin concentration during the OGTT (30-120 min). C. After a 12-h fast, male rats received an i.v. injection of either VEH $(0.9 \% \mathrm{NaCl}$; adult rats $=3$, old rats $=5)$ or NRG1 (50 $\mu \mathrm{g} / \mathrm{kg}$; adult rats $=3$, old rats =5) and were euthanized 30 min later. For Western blot analysis, liver protein extracts were probed with antibodies against IRS-1, p-IRS-1 (Ser307) and p-IRS1 (Ser638). Phosphorylation ratios (phosphorylated protein/total protein) of IRS-1 on (D) Ser307 and (E) Ser638 were calculated and normalized to values obtained in the adult VEH group. Values are means \pm SEM. 
A
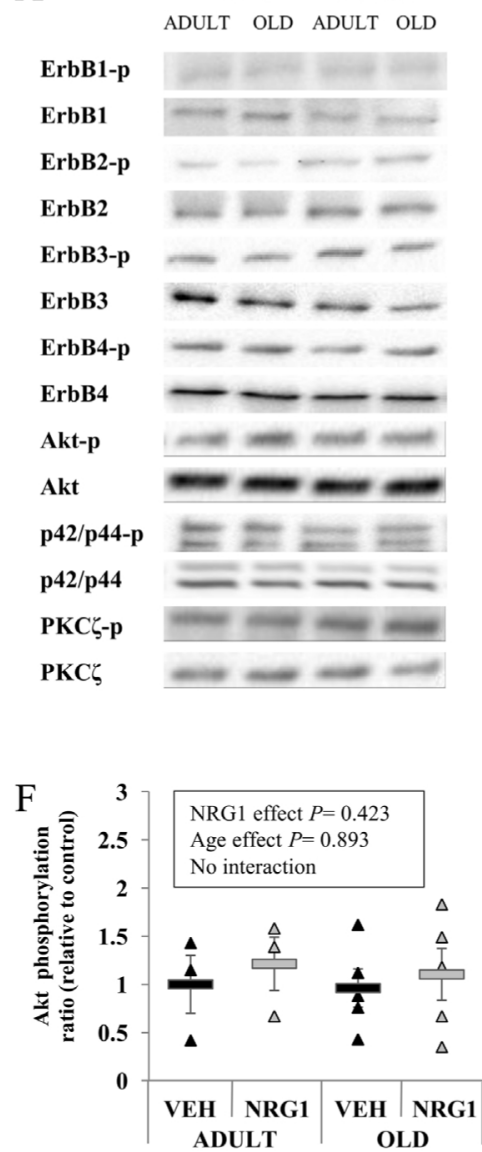
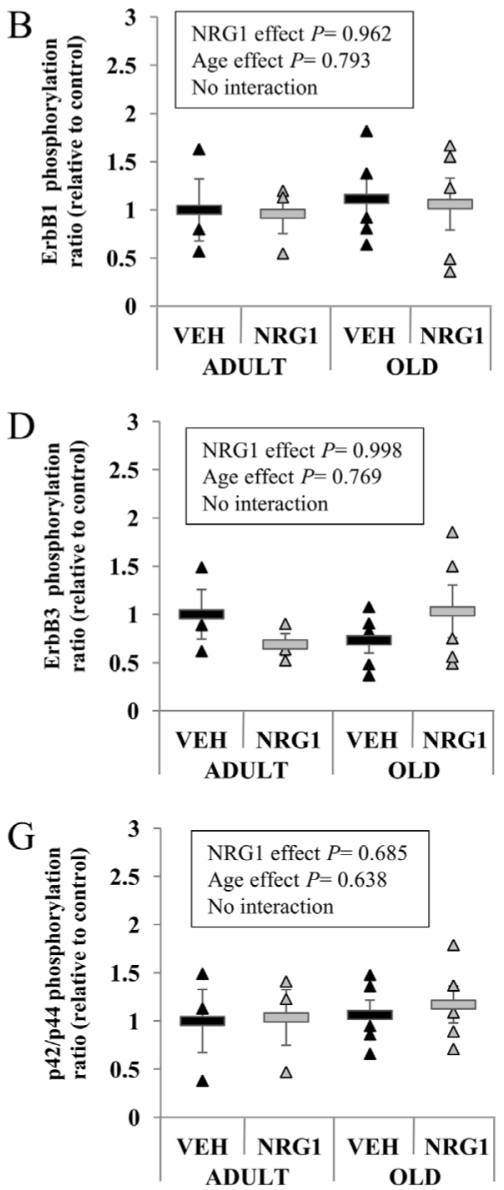

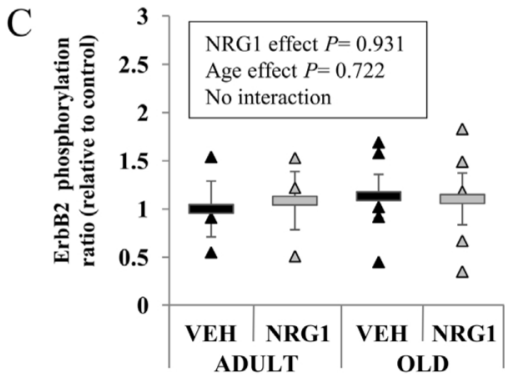

$\mathrm{E}$

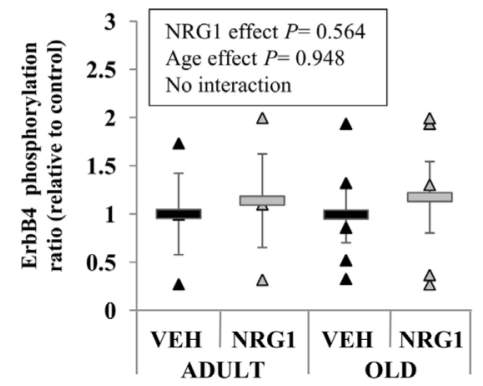

$\mathrm{H}$

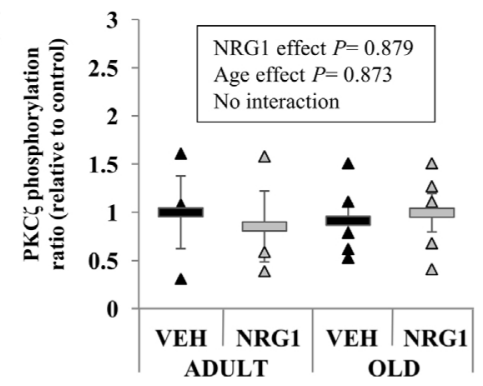

Fig. 4. Effects of acute injection of NRG1 on ErbB, AKT, p42/p44 and PKC $\zeta$ phosphorylation ratios in gastrocnemius muscle from adult and old rats. After a 12-h fast, male adult $(n=3)$ and old $(n=5)$ rats received an i.v. injection of VEH $(0.9 \% \mathrm{NaCl})$ or NRG1 $(50 \mu \mathrm{g} / \mathrm{kg})$ and were euthanized $30 \mathrm{~min}$ later. A. For Western blot analysis, protein extracts from this skeletal muscle were probed with antibodies directed against basal and phosphorylated ErbB1, ErbB2, ErbB3, ErbB4, p42/p44, AKT and PKCל. Phosphorylation ratios (protein-p/total protein) of (B) ErbB1 on Tyr1173, (C) ErbB2 on Tyr1248, (D) ErbB3 on Tyr1328, (E) ErbB4 on Tyr1056, (F) AKT on Ser473, (G) p42/p44 on Thr202/Tyr204 and (H) PKC $\zeta$ on Thr410 were calculated. Ratios were normalized to values obtained in the adult VEH group. Values are means \pm SEM.

After treatment, ErbB phosphorylation ratios in the gastrocnemius were not significantly different between adult and old rats or between NRG1- and VEH-treated rats (no age $\times$ NRG1 interaction; Fig. 4B-E). Similarly, phosphorylation ratios of AKT (Ser473), p42/p44 MAPK (Thr202/Tyr204) and PKC $\xi$ (Thr410), three kinases activated by transactivation of ErbB receptors, were not significantly affected by the acute NRG1 injection (Fig. 4F-H). Likewise, AMPK phosphorylation, which is involved in glucose transporter translocation in skeletal muscle [22], was not modified following NRG1 injection (data not shown). To further confirm that NRG1 does not target skeletal muscle glucose homoeostasis, isolated rat epitrochlearis muscle samples were incubated with either NRG1 or insulin. While insulin stimulated 2-deoxyglucose uptake, NRG1 had no effect (data not shown).

In liver, insulin receptor substrate (IRS)-1 phosphorylation on Ser307 and Ser638 was not increased by NRG1 treatment (Fig. 3). On the other hand, the ErbB3 phosphorylation ratio was significantly increased in NRG1- compared with VEHtreated animals independent of age (NRG1 effect: $P=0.009$; Fig. 5A-C). ErbB1, ErbB2 and ErbB4 phosphorylation ratios were not affected by NRG1, whereas AKT phosphorylation was significantly increased in both adult and old rats after NRG1 treatment (NRG1 effect: $P=0.002$ ). Neither an age effect nor age $\times$ NRG1 interaction was observed (Fig. 5D).

\section{Discussion}

The aim of the present study was to determine whether the NRG1/ErbB signaling pathway can influence whole-body glucose metabolism and, if so, whether the effect is age-dependent. Our results indicate that an acute NRG1 injection improves glucose tolerance following oral glucose loading in both adult and old rats. The HIRI derived from OGTTs was also improved after acute NRG1 injection, while the MISI remained unchanged. Also, acute NRG1 injection activated the ErbB3 pathway in liver, but not skeletal muscle, in both rat groups. Taken altogether, these results show that acute NRG1 injection can improve glucose metabolism in vivo in adult and old rats. The liver appears to be the main tissue involved in the NRG1-induced hypoglycaemic effect. 

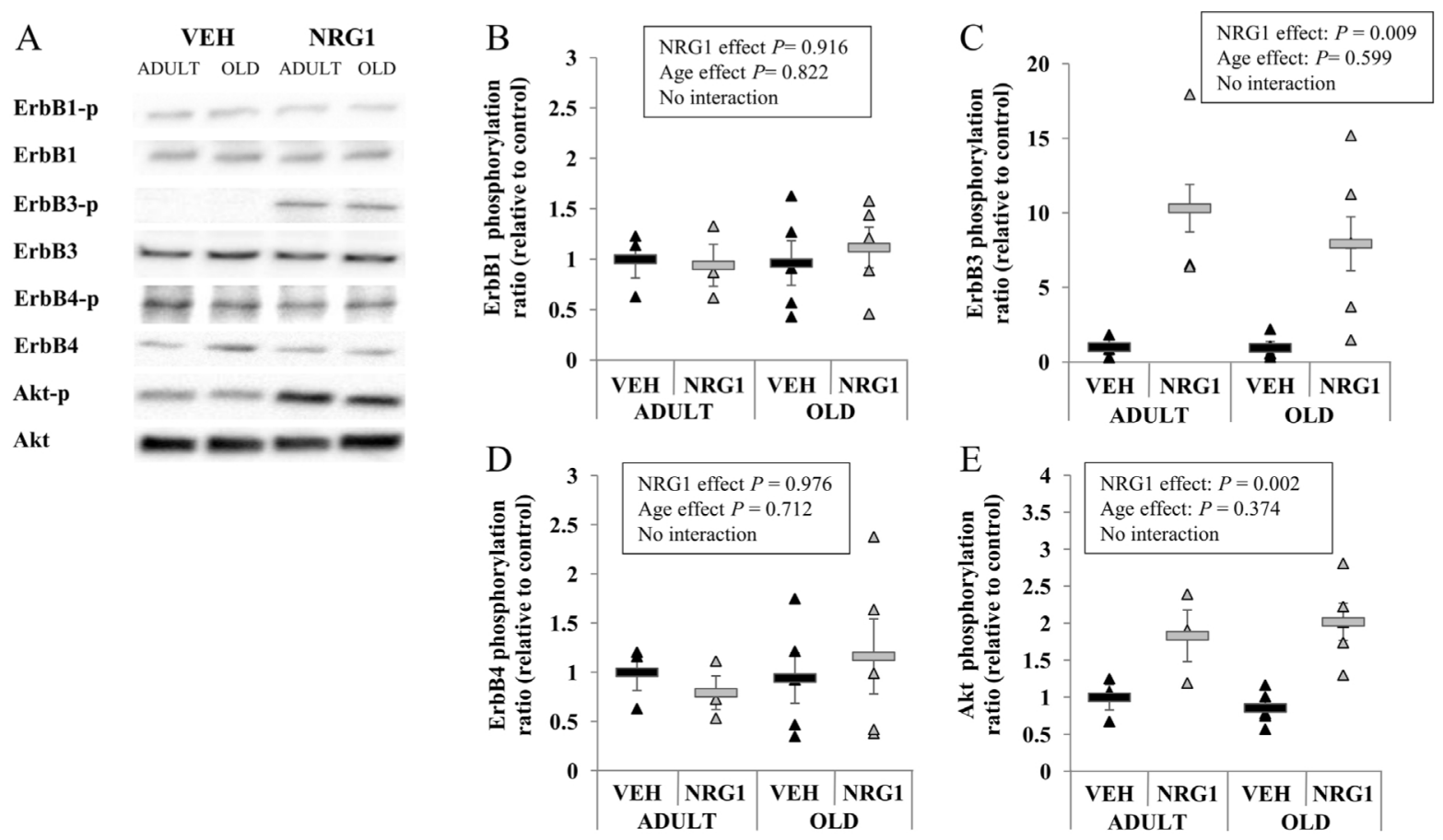

Fig. 5. Effects of acute injection of NRG1 on ErbB and AKT phosphorylation ratios in the liver of adult and old rats. After a 12-h fast, male adult ( $n=3$ ) and old $(n=5)$ rats received an i.v. injection of either VEH $(0.9 \% \mathrm{NaCl})$ or NRG1 $(50 \mu \mathrm{g} / \mathrm{kg})$ and were euthanized 30 min later. A. Western blot analyses used liver protein extracts and antibodies against basal and phosphorylated ErbB1, ErbB3, ErbB4 and AKT. Phosphorylation ratios (phosphorylated protein/total protein) of (B) ErbB1 on Tyr1173, (C) ErbB3 on Tyr1328, (D) ErbB4 on Tyr1056 and (E) AKT on Ser473 were calculated and normalized to values obtained in the adult VEH group. Values are means \pm SEM.

Skeletal muscle is the main tissue involved in glucose disposal following an oral glucose load, and skeletal muscle insulin resistance is a major contributor to the impaired glucose tolerance associated with type 2 diabetes [23]. Therefore, an NRG1-induced increase in skeletal muscle glucose uptake is an attractive hypothesis to explain the NRG1 hypoglycaemic effect. Indeed, previous studies in vitro with L6E9 cells showed that NRG1 increases glucose uptake in an additive manner similar to insulin $[9,24]$. This effect is mediated by translocation of glucose transporter 4 (GLUT4) to the sarcolemma via the ErbB3/PI3Kdependent signaling pathway $[9,24]$. In contrast, our present results show that the OGTT-derived MISI is not affected by acute injection of NRG1, suggesting that skeletal muscle is not the primary tissue involved in the NRG1-induced hypoglycaemic effect in vivo. Accordingly, Western blot analysis of ErbB phosphorylation in skeletal muscle samples following acute NRG1 injection showed no ErbB activation. Moreover, AKT, p42/p44 MAPK and PKC $\zeta$, three kinases involved in ErbB downstream signaling, were not activated by NRG1 injection. Our study also confirms, in isolated rat gastrocnemius samples, that NRG1 incubation does not increase glucose uptake in skeletal muscle (data not shown).

Two hypotheses could explain the discrepancy with previous results in vitro [9,24]. First, adult skeletal muscle in vivo might respond differently to NRG1 compared with cultured myoblasts. ErbB receptors are, in fact, weakly expressed in the skeletal muscle of adult rodents compared with $\mathrm{C} 2 \mathrm{C} 12$ cells and primary rat myoblasts [25]. In addition, the finding that ErbB1 and ErbB3 are more strongly expressed in liver than in skeletal muscle strengthens the hypothesis that weak expression of some ErbB receptors could reduce NRG1 signaling in skeletal muscle. Second, our adult and old rats were treated with recombinant $\beta 2$ NRG1 [26], whereas myoblasts were incubated with $\beta 1-N R G 1$ $[10,24,27]$. Thus, it may be hypothesized that, in skeletal muscle, ErbB receptors are less sensitive to $\beta 2-\mathrm{NRG} 1$ than to $\beta 1$-NRG1.

In contrast to the MISI, the HIRI was lowered by acute NRG1 injection in both adult and old rats. This suggests involvement of the liver in the NRG1 hypoglycaemic effect. OGTT-derived HIRI values reflect the magnitude of rises in glycemia and insulinaemia in the early phase $(0-30 \mathrm{~min})$ following glucose loads, and this correlates with hepatic insulin resistance [20]. However, very few studies have explored NRG1 effects in liver. Carver et al. [12] showed, in rat hepatocytes, that insulin impairs NRG1 fixation on ErbB3 and decreases ErbB3 expression through the PI3K pathway. Conversely, ErbB2/ErbB3 transactivation induces IRS-1 serine phosphorylation, which inhibits its tyrosine phosphorylation and decreases ErbB2/ErbB3 in association with PI3K [28]. More recently, Hemi et al. [13] confirmed in ob/ob mice that p38 MAPK-dependent ErbB receptor transactivation induces IRS-1 serine phosphorylation.

Based on those previous studies, the hypothesis that NRG1 might improve hepatic insulin sensitivity is unlikely. On the other hand, it could be hypothesized that NRG1 disturbs insulin signaling in the liver. However, levels of IRS-1 phosphorylation on Ser307 and Ser638 (two residues phosphorylated by p38 MAPK-dependent ErbB activation) are not increased in NRG1-treated animals. Thus, transactivation of ErbB receptors induced by p38 MAPK-dependent stress could trigger different 
signaling cascades compared with those induced by NRG1 injection, which has no effect on IRS-1 signaling.

Our present results show that NRG1 injection induces significant ErbB3 activation in liver, reinforcing the hypothesis that the NRG1 hypoglycaemic effect might be at least partly mediated through hepatic regulation. As other ErbB receptors are not phosphorylated and ErbB3 receptors are kinase-inactive [29], it could be suggested that NRG1 injections favor dimerization of ErbB3 with another ErbB receptor that then transphosphorylates ErbB3. As ErbB1 is strongly expressed in liver, ErbB1-ErbB3 could be the main dimer formed after NRG1 injection. Indeed, it has previously been shown in different cell lines that NRG1 can induce ErbB1-ErbB3 dimerization, increasing ErbB3, but not ErbB 1, phosphorylation $[30,31]$. The finding that AKT phosphorylation was also increased in liver following NRG1 injection offers a potential explanation for the glucose-lowering effect of NRG1. AKT is a major regulator of insulin-mediated inhibition of glucose production in liver, mainly through modulation of the expression of genes encoding gluconeogenic proteins [32]. The reduced blood glucose levels observed in NRG1-treated rats could also be linked to an NRG1 effect on pancreatic insulin secretion. However, unlike NRG4, NRG1 does not increase insulin production in the rat islet-derived cell line CRI-G1 [33]. Furthermore, in the present study, plasma insulin levels during OGTTs were not higher in the NRG1-treated vs VEH-treated animals.

In both humans and rats, ageing is associated with elevated glucose and insulin levels after glucose challenge tests [34,35]. This has been partly attributed to the development of whole-body insulin resistance with ageing [36]. In our study, as expected, age-related higher glucose and insulin levels were observed in both old groups (NRG1- and VEH-treated) during OGTT. However, no age $\times$ NRG1 interaction was found with glucose and insulin responses. Thus, if NRG1 treatment has a hypoglycaemic effect during an oral glucose challenge, such an effect is lacking in 22-month-old animals. This was also confirmed at the cellular level, wherein NRG1 injection increased hepatic ErbB3 and AKT phosphorylation in both adult and 22-month-old rats. As insulin signaling in liver is progressively impaired with ageing, the fact that NRG1 maintains its glucose-lowering activity in 22-month-old animals suggests that the NRG1/ErbB signaling pathway could be a promising therapeutic target in glucose intolerance states such as ageing. Nevertheless, the possibility that older animals might present with some defects of NRG1 signaling cannot be ruled out.

\section{Conclusion}

The present study shows that acute NRG1 injection improves glucose tolerance during OGTTs in 6-month-old and 22-monthold rats. The NRG1 glucose-lowering effect appears to involve the liver, but not skeletal muscle. NRG1 failed to increase ErbB phosphorylation levels in skeletal muscle, whereas ErbB3 and AKT phosphorylation was significantly induced in liver. Finally, no age $\times$ NRG1 interaction was noted for OGTT responses and liver ErbB phosphorylation.
These results indicate that NRG1 might be a therapeutic target of interest in conditions of insulin resistance in both young rats and animals in the early stages of ageing. Further experiments are needed to determine precisely how the numerous isoforms of NRG1 influence the regulation of glucose homoeostasis and to explore the effects of chronic NRG1 treatments.

\section{Disclosure of interest}

\section{Xinyan Li is employed by Zensun Sci \& Tech Ltd.}

\section{Acknowledgements}

The rhNRG1 used in the study was kindly provided by Zensun Sci \& Tech Ltd, Shanghai, People's Republic of China. The authors wish to thank Chistophe Del'homme for animal husbandry and skilful technical assistance, Elisabetta Andermarcher for language help and writing assistance, Bruno Pereira for statistical analysis help, and Anna Guma for helpful discussions and suggestions.

\section{References}

[1] Falls DL. Neuregulins: functions, forms, and signaling strategies. Exp Cell Res 2003;284:14-30.

[2] Meyer D, Yamaai T, Garratt A, Riethmacher-Sonnenberg E, Kane D, Theill LE, et al. Isoform specific expression and function of neuregulin. Development 1997; 124:3575-86.

[3] Fricker FR, Lago N, Balarajah S, Tsantoulas C, Tanna S, et al. Axonally derived neuregulin- 1 is required for remyelination and regeneration after nerve injury in adulthood. J Neurosci 2011;31:3225-33.

[4] Zhao YY, Sawyer DR, Baliga RR, Opel DJ, Han X, et al. Neuregulins promote survival and growth of cardiac myocytes. Persistence of ErbB2 and ErbB4 expression in neonatal and adult ventricular myocytes. J Biol Chem 1998;273:10261-9.

[5] Guma A, Martinez-Redondo V, López-Soldado I, Cantó C, Zorzano A. Emerging role of neuregulin as a modulator of muscle metabolism. Am J Physiol Endocrinol Metab 2010;298:E742-50.

[6] Yoshioka T, Nishikawa Y, Ito R, Kawamata M, Doi Y, et al. Significance of integrin alphavbeta5 and erbB3 in enhanced cell migration and liver metastasis of colon carcinomas stimulated by hepatocyte-derived heregulin. Cancer science 2010;101:2011-8.

[7] Yarden Y, Sliwkowski MX. Untangling the ErbB signalling network. Nature reviews. Molecular cell biology 2001;2:127-37.

[8] Zorzano A, Kaliman P, Gumà A, Palacín M. Intracellular signals involved in the effects of insulin-like growth factors and neuregulins on myofibre formation. Cellular signalling 2003;15:141-9.

[9] Suárez E, Bach D, Cadefau J, Palacin M, Zorzano A, Gumá A. A novel role of neuregulin in skeletal muscle. Neuregulin stimulates glucose uptake, glucose transporter translocation, and transporter expression in muscle cells. J Biol Chem 2001;276:18257-64.

[10] Canto C, Pich S, Paz JC, Sanches R, Martínez V, Orpinell M, et al. Neuregulins increase mitochondrial oxidative capacity and insulin sensitivity in skeletal muscle cells. Diabetes 2007:2185-93.

[11] Carver RS, Sliwkowski MX, Sitaric S, Russell WE. Insulin regulates heregulin binding and ErbB3 expression in rat hepatocytes. J Biol Chem 1996;271:13491-6.

[12] Carver RS, Mathew PM, Russell WE. Hepatic expression of ErbB3 is repressed by insulin in a pathway sensitive to PI-3 kinase inhibitors. Endocrinology 1997;138:5195-201.

[13] Hemi R, Yochananov Y, Barhod E, Kasher-Meron M, Karasik A, Tirosh A, et al. p38 mitogen-activated protein kinase-dependent transactivation of ErbB receptor family: a novel common mechanism for 
stress-induced IRS-1 serine phosphorylation and insulin resistance. Diabetes 2011;60:1134-45.

[14] Paolisso G, Scheen A, Lefèbvre P. Glucose handling, diabetes and ageing. Horm Res 1995;43:52-7.

[15] Yamaza H, Chiba T, Higami Y, Shimokawa I. Lifespan extension by caloric restriction: an aspect of energy metabolism. Microsc Res Tech 2002;59:325-30.

[16] Rohrbach S, Niemann B, Abushouk AM, Holtz J. Caloric restriction and mitochondrial function in the ageing myocardium. Exp Gerontol 2006;41:525-31.

[17] Dickerson JW, Hemmerle AM, Numan S, Lundgren KH, Seroogy KB. Decreased expression of ErbB4 and tyrosine hydroxylase mRNA and protein in the ventral midbrain of aged rats. Neuroscience 2009;163:482-9.

[18] Edrey YH, Casper D, Huchon D, Mele J, Gelfond JA, Kristan DM, et al. Sustained high levels of neuregulin-1 in the longest-lived rodents; a key determinant of rodent longevity. Aging Cell 2012;11:213-22.

[19] He K, Zhou T, Shao J, Ren X, Zhao Z, Liu D. Dynamic regulation of genetic pathways and targets during aging in Caenorhabditis elegans. Aging (Albany NY) 2014;6:215-30.

[20] Abdul-Ghani MA, Matsuda M, Balas B, DeFronzo RA. Muscle and liver insulin resistance indexes derived from the oral glucose tolerance test. Diabetes Care 2007;30:89-94.

[21] Gilda JE, Gomes AV. Western blotting using in-gel protein labeling as a normalization control: stain-free technology. Methods Mol Biol 2015;1295:381-91.

[22] Schultze S, Hemmings B, Niessen M, Tschopp O. PI3K/AKT, MAPK and AMPK signalling: protein kinases in glucose homeostasis. Expert Rev Mol Med 2012;14:e1.

[23] DeFronzo RA, Tripathy D. Skeletal muscle insulin resistance is the primary defect in type 2 diabetes. Diabetes Care 2009;32(Suppl 2):S157-63.

[24] Cantó C, Suárez E, Lizcano JM, Griñó E, Shepherd PR, Fryer LG, et al. Neuregulin signaling on glucose transport in muscle cells. J Biol Chem 2004;279:12260-8.

[25] Huang YZ, Wang Q, Won S, Luo ZG, Xiong WC, Mei L. "Compartmentalized NRG signaling and PDZ domain-containing proteins in synapse structure and function.". Int J Dev Neurosci 2002;20: $173-85$.

[26] Liu X, Gu X, Li Z, Li X, Li H, Chang J, et al. Neuregulin-1/erbB-activation improves cardiac function and survival in models of ischemic, dilated, and viral cardiomyopathy. J Am Coll Cardiol 2006;48:1438-47.

[27] Canto C, Chibalin AV, Barnes BR, Glund S, Suárez E, Ryder JW, et al. Neuregulins mediate calcium-induced glucose transport during muscle contraction. J Biol Chem 2006;281:21690-7.

[28] Hemi R, Paz K, Wertheim N, Karasik A, Zick Y, Kanety H. Transactivation of ErbB2 and ErbB3 by tumor necrosis factor-alpha and anisomycin leads to impaired insulin signaling through serine/threonine phosphorylation of IRS proteins. J Biol Chem 2002;277:8961-9.

[29] Guy P, Platko J, Cantley LC, Cerione RA, Carraway 3rd KL. Insect cellexpressed p180erbB3 possesses an impaired tyrosine kinase activity. Proc Natl Acad Sci USA 1994;91:8132-6.

[30] Khan I, Zhao J, Ghosh P, Ziman M, Sweeney C, Kung HJ, et al. Microbead arrays for the analysis of ErbB receptor tyrosine kinase activation and dimerization in breast cancer cells. Assay Drug Dev Techno 2010;8:27-36.

[31] Frolov A, Schuller K, Tzeng CW, Cannon EE, Ku BC, Howard JH, et al. ErbB3 expression and dimerization with EGFR influence pancreatic cancer cell sensitivity to erlotinib. Cancer Biol Ther 2007;6:548-54.

[32] Whiteman EL, Cho H, Birnbaum MJ. Role of Akt/protein kinase B in metabolism. Trends Endocrinol Metab 2002;13:444-51.

[33] South JC, Blackburn E, Brown IR, Gullick WJ. The neuregulin system of ligands and their receptors in rat islets of langerhans. Endocrinology 2013;154:2385-92.

[34] Davidson MB. The effect of aging on carbohydrate metabolism: a review of the English literature and a practical approach to the diagnosis of diabetes mellitus in the elderly. Metabolism 1979;28:688-705.

[35] Curry DL, Reaven G, Reaven E. Glucose-induced insulin secretion by perfused pancreas of 2- and 12-mo-old Fischer 344 rats. Am J Physio 1984;247(3 Pt 1):E385-8.

[36] Kalyani RR, Egan JM. Diabetes and altered glucose metabolism with aging. Endocrinol Metab Clin North Am 2013;42:333-47. 